\title{
Predictors of re-intervention after greenlight laser photoselective vaporization of the prostate: multicenter long/mid-term follow-up experience
}

\author{
Davide Campobasso', Michele Marchioni ${ }^{2}$, Cosimo De Nunzio ${ }^{3}$, Paolo Destefanis ${ }^{4}$, Giuseppe Fasolis ${ }^{5}$, \\ Francesco Varvello ${ }^{5}$, Salvatore Voce ${ }^{6}$, Giulio Reale ${ }^{6}$, Tommaso Cai ${ }^{7}$, Gianni Malossini ${ }^{8}$, Rino Oriti ${ }^{9}$, \\ Agostino Tuccio $^{10}$, Lorenzo Ruggera ${ }^{11}$, Andrea Tubaro ${ }^{3}$, Francesco Greco ${ }^{12}$, Antonino Laganà ${ }^{13}$, Claudio \\ Dadone $^{14}$, Paolo Gontero ${ }^{4}$, Gaetano De Rienzo ${ }^{15}$, Luigi Pucci ${ }^{16}$, Maurizio Carrino ${ }^{16}$, Francesco Montefiore ${ }^{17}$, \\ Salvatore Rabito ${ }^{18}$, Stefano Germani ${ }^{19}$, Roberto Miano ${ }^{19}$, Luigi Schips ${ }^{2}$, Antonio Frattini ${ }^{1}$, Giovanni Ferrari ${ }^{18}$, \\ Luca Cindolo ${ }^{20}$ \\ 'Urology Unit, Civil Hospital of Guastalla, Azienda USL-IRCCS di Reggio Emilia, Guastalla, RE 42016, Italy. \\ 2Department of Medical, Oral and Biotechnological Sciences, "G. D'Annunzio" University of Chieti, Chieti, CH 66100, Italy. \\ ${ }^{3}$ Department of Urology, "Sant' Andrea” Hospital, Sapienza University, Roma, RM 00189, Italy. \\ ${ }^{4}$ Department of Urology, Azienda Ospedaliera Città della Salute e della Scienza di Torino - Sede Molinette, Torino, TO 10126, \\ Italy. \\ 5Department of Urology, "S. Lazzaro" Hospital, Alba, CN 12051, Italy. \\ ${ }^{6}$ Department of Urology, "Santa Maria delle Croci Hospital", Ravenna, RA 48121, Italy. \\ ${ }^{7}$ Department of Urology, Santa Chiara Regional Hospital, Trento, TN 38122, Italy. \\ ${ }^{8}$ Department of Urology, "Rovereto Hospital", Rovereto, TN 38068, Italy. \\ 'Department of Urology, "Ulivella e Glicini Clinic", Firenze, FI 50139, Italy. \\ ${ }^{10}$ Department of Urology, University of Florence, Unit of Oncologic Minimally-Invasive Urology and Andrology, Careggi Hospital, \\ Firenze, FI 50134, Italy. \\ ${ }^{11}$ Department of Urology, Clinica urologica azienda ospedaliera - University of Padova, Padova, PD 35126, Italy. \\ ${ }^{12}$ Urologic Clinic, Centro Salute Uomo, Bergamo, BG 24121, Italy. \\ ${ }^{13}$ Department of Urology, "S. Giovanni Evangelista" Hospital, Tivoli, RM 00019, Italy. \\ ${ }^{14}$ Department of Urology, "Santa Croce e Carle" Hospital, Cuneo, CN 12100, Italy. \\ ${ }^{15}$ Department of Emergency and Organ Transplantation, Urology and Andrology Unit II, University of Bari, Bari, BA 70121, Italy. \\ ${ }^{16}$ Department of Urology, AORN “Antonio Cardarelli", Napoli, NA 80131, Italy. \\ ${ }^{17}$ Department of Urology, "San Giacomo" Hospital, Novi Ligure, AL 15067, Italy. \\ ${ }^{18}$ Department of Urology, "Hesperia Hospital", Modena, MO 41121, Italy. \\ ${ }^{19}$ UOSD Urologia, Fondazione Policlinico Tor Vergata, Roma, RM 00133, Italy. \\ ${ }^{20}$ Department of Urology, “Villa Stuart" Private Hospital, Roma, RM 00135, Italy.
}

Correspondence to: Davide Campobasso, MD, Urology Unit, Civil Hospital of Guastalla, Azienda USL-IRCCS di Reggio Emilia, Via Donatori di Sangue, Guastalla, RE 1-42016, Italy. E-mail: d.campobasso@virgilio.it

How to cite this article: Campobasso D, Marchioni M, De Nunzio C, Destefanis P, Fasolis G, Varvello F, Voce S, Reale G, Cai T, Malossini G, Oriti R, Tuccio A, Ruggera L, Tubaro A, Greco F, Laganà A, Dadone C, Gontero P, De Rienzo G, Pucci L, Carrino M, Montefiore F, Rabito S, Germani S, Miano R, Schips L, Frattini A, Ferrari G, Cindolo L. Predictors of re-intervention after greenlight laser photoselective vaporization of the prostate: multicenter long/mid-term follow-up experience. Mini-invasive Surg 2021;5:45. https://dx.doi.org/10.20517/2574-1225.2021.92

Received: 29 Jul 2021 Accepted: 6 Sep 2021 Available online: 10 Sep 2021 
Academic Editors: Richard Lawrence John Naspro, Giulio Belli Copy Editor: Xi-Jun Chen Production Editor: Xi-Jun Chen

\begin{abstract}
Aim: Greenlight photoselective vaporization of the prostate (PVP) is considered a safe alternative to transurethral resection of the prostate (TURP) in men with lower urinary tract symptoms (LUTS) and a prostate volume of 30$80 \mathrm{~mL}$ for the comparable short- and mid-term results. Long-term re-treatment rate is still being debated.
\end{abstract}

Methods: We retrospectively reviewed greenlight PVP procedures in a multi-institutional database from September 2011 to December 2019 collecting data on patients requiring re-intervention with a follow-up period of at least 12 months.

Results: Among 867 patients with a median follow-up period of 32.5 months (interquartile range: 20.0-49.0 months), 35 patients (4\%) required re-intervention. Patients requiring re-intervention had a prostate volume $\geq$ $100 \mathrm{~mL}$ in $28.6 \%$ of cases $(P=0.002)$. Preoperative urethral stricture and incidence of early complications were more frequent in the re-treatment group $(P=0.027$ and $P=0.006)$. In the re-treatment group, 22 patients required an endoscopic intervention for bladder neck or prostatic fossa contracture ( $2.5 \%$ of the study population). The remaining 13 patients in the re-treatment group underwent TURP or PVP for LUTS relapse $(1.5 \%)$. In the univariate and multivariate logistic regression models, only prostate volume $\geq 100 \mathrm{~mL}(P=0.003$ and $P=0.010)$, preoperative urethral stricture $(P=0.013$ and $P=0.036)$, and occurrence of early complications $(P=0.008$ and $P$ $=0.024)$ correlated with re-intervention.

Conclusion: Greenlight PVP has good functional long/mid-term results. The presence of preoperative urethral stricture and the occurrence of early complications correlate with the risk of late re-treatment. In patients with prostate $\geq 100 \mathrm{~mL}$, the enucleation technique may be superior to vaporization in terms of lower long-term risk of re-intervention for LUTS relapse.

Keywords: Greenlight laser, long-term results, re-intervention

\title{
INTRODUCTION
}

Benign prostatic obstruction (BPO) causing lower urinary tract symptoms (LUTS) is present in up to $80 \%$ of men over the age of 80 and in up to $50 \%$ of men over the age of 50, resulting in significant economic burden and potentially negative impact on the quality of life $\mathrm{e}^{[1]}$. Pharmacological management with alpha 1-blockers or combination therapies (alpha 1-blockers + 5-alpha-reductase inhibitors or alpha 1-blockers + muscarinic receptor antagonists) is the first-line treatment. Surgical treatment is indicated in the case of pharmacological management failure or discontinuation ${ }^{[2-4]}$. Nowadays, despite the availability of several laser technologies (holmium, greenlight, diode, and thulium), monopolar or bipolar transurethral resection of the prostate (M- or B-TURP) is considered the first-line treatment for patients with moderate-to-severe LUTS and a prostate volume of 30-80 mL, due to the absence of long-term surgical randomized controlled trials on laser treatments ${ }^{[2]}$. The longer catheterization time and hospital stay, with a higher risk of hemorrhagic complications in transurethral resection of the prostate (TURP) series in comparison to laser series $^{[5]}$, are increasing the use of lasers in the treatment of BPO. Some limitations preventing further spreading of holmium laser enucleation of the prostate (HoLEP) and thulium vapoenucleation of the 
prostate (ThuVEP) are a long learning curve and the need for further materials regarding morcellation. The 180-W LBO crystal Green Light Xcelerated Performance System (XPS) ${ }^{\mathrm{TM}}$ (American Medical System-AMS, Minnetonka, Minnesota) and the new $532 \mathrm{~nm}$ wavelength, metal-capped and liquid cooled irrigated fiber (Moxy TM fiber) with its different and versatile uses [standard photovaporization (PVP), anatomical PVP, and greenlight enucleation of prostate (GreenLEP)] have allowed us to overcome these drawbacks ${ }^{[6,7]}$. Current guidelines consider greenlight laser as an alternative to TURP in men with moderate-to-severe LUTS and a prostate volume of 30-80 mL, in light of their comparable short- and mid-term results ${ }^{[3,7]}$. Moreover, some evidence is emerging supporting the use of greenlight laser also for large volume prostates and in men on anticoagulation or with high cardiovascular risk ${ }^{[8-11]}$. According to the current literature, the major limitation of greenlight is the absence of long-term follow-up ( $\geq 36$ months) data to evaluate the outcome, the rate of re-intervention, and patient satisfaction. For these reasons, we decided to review and update our large multicenter cohort of patients who have undergone greenlight laser treatment in order to analyze the long-term re-treatment rate and risk factors for treatment failure.

\section{METHODS}

We retrospectively reviewed all cases undergoing standard or anatomical greenlight laser photoselective vaporization of the prostate for lower urinary tract symptoms secondary to BPO, using the 180-W XPS GL system, in a multi-institutional, prospectively collected database performed in 20 Italian centers from September 2011 to December 2019, and collecting data on patients developing LUTS relapse requiring reintervention (TURP or greenlight PVP) with a follow-up period of at least 12 months. Surgeons with consolidated experience in greenlight PVP performed all considered procedures. Informed consent was obtained from all individual participants included in the study. This study was approved by the institutional research ethical committee and all related procedures were conducted in accordance with the Declaration of Helsinki. Patients with all the following data were considered in the statistical analysis: age, prostate volume evaluated with trans-rectal ultrasound (TRUS), use of antiplatelet and anticoagulant medications, LUTS therapy and history of catheterization or retention, PSA level, IPSS, maximum urinary flow (Qmax), operative time, lasing time, catheterization time, hospital stay, and complications. The Clavien-Dindo classification was used to describe reported complications and divided into early (30 days) or late (> 30 days) complications ${ }^{[12,13]}$. Postoperative frequency and urgency were considered as complications when they prompted additional medical examination or when reported by patients affecting the Patient Global Impression of Improvement scale (PGI-I) ${ }^{[14]}$. The presence of any degree and type of incontinence (stress or urge incontinence) reported by the patients and impairing their quality of life was defined as urinary incontinence. All patients underwent an outpatient clinic evaluation after at least 6 and 12 months and then annually with IPSS, Qmax, PSA level, and the PGI-I scale. Follow-up was calculated as the time from surgery to the last visit. Patients with a history of prostate cancer, neurogenic bladder disease, and previous prostate surgery, as well as those who underwent GreenLEP or contemporary treatment of bladder stones, including incidental bladder tumors, were not considered in this study.

\section{Statistical analysis}

Quantitative variables were summarized as median and interquartile range (IQR). Qualitative data were summarized as frequency and percentage. After stratification according to reintervention performance, the Chi-square and the Mann-Whitney $U$ tests were used to test the statistical significance in proportions and median differences. We relied on univariable and multivariable logistic regression models to test main predictors of reintervention. Multivariable logistic regression models included covariates that were statistically significant at univariable analysis. All tests were two-sided, and the level of statistical significance was set at $P<0.05$. Analyses were performed using the $\mathrm{R}$ software environment for statistical computing and graphics (version 4.0.5; http://www.r-project.org/). 
Table 1. Values are $n$ (\%) or median interquartile range. Patients' preoperative and intraoperative characteristics

\begin{tabular}{|c|c|c|c|c|}
\hline & $\begin{array}{l}\text { No re-intervention } \\
n=832\end{array}$ & $\begin{array}{l}\text { Re-intervention } \\
n=35\end{array}$ & $\begin{array}{l}\text { Overall } \\
n=867\end{array}$ & $P$ value \\
\hline Age (years) & $68.0(63.0-75.0)$ & $70.0(64.0-74.0)$ & $68.0(63.0-75.0)$ & 0.696 \\
\hline Prostate volume, TRUS (mL) & $60.0(45.0-75.0)$ & $65.0(45.0-100.0)$ & $60.0(45.0-75.5)$ & 0.236 \\
\hline Antiplatelet/anticoagulant therapy & & & & 0.535 \\
\hline None & $485(58.3 \%)$ & $20(57.1 \%)$ & $505(58.2 \%)$ & \\
\hline Antiplatelet & $239(28.7 \%)$ & $9(25.7 \%)$ & $248(28.6 \%)$ & \\
\hline Anticoagulant & $91(10.9 \%)$ & $4(11.4 \%)$ & $95(11.0 \%)$ & \\
\hline Unknown & $17(2.0 \%)$ & $2(5.7 \%)$ & $19(2.2 \%)$ & \\
\hline BPH/LUTS therapy & & & & 0.808 \\
\hline None & $131(15.7 \%)$ & $6(17.1 \%)$ & $137(15.8 \%)$ & \\
\hline Alpha-blockers & $404(48.6 \%)$ & $19(54.3 \%)$ & $423(48.8 \%)$ & \\
\hline $5-A R I$ & $48(5.8 \%)$ & $1(2.9 \%)$ & $49(5.7 \%)$ & \\
\hline Combination & $249(29.9 \%)$ & $9(25.7 \%)$ & $258(29.8 \%)$ & \\
\hline Indwelling catheter history & $118(14.2 \%)$ & $9(25.7 \%)$ & $127(14.6 \%)$ & 0.059 \\
\hline Operative time (min) & $55.0(40.0-75.0)$ & $55.0(40.0-65.0)$ & $55.0(40.0-75.0)$ & 0.778 \\
\hline Lasing time (min) & $25.0(18.0,34.0)$ & $24.0(17.0,38.0)$ & $25.0(18.0,34.0)$ & 0.978 \\
\hline Catheterization time (days) & $1.0(1.0,2.0)$ & $2.0(1.0,2.0)$ & $1.0(1.0,2.0)$ & 0.841 \\
\hline Postoperative stay (days) & $2.0(1.0,2.0)$ & $2.0(1.0,2.0)$ & $2.0(1.0,2.0)$ & 0.529 \\
\hline Early complications & $352(42.3 \%)$ & $23(65.7 \%)$ & $375(43.3 \%)$ & 0.006 \\
\hline
\end{tabular}

TRUS: Trans-rectal ultrasound; LUTS: lower urinary tract symptoms; 5-ARI: 5 alpha-reductase inhibitors.

\section{RESULTS}

Among 885 patients with at least 12 months of follow-up, 18 patients with postoperative urethral stricture (2\%) were excluded from the analysis. In total, 867 patients with a follow-up of at least 12 months and all the required data for inclusion were considered for analysis. With a median follow-up period of 32.5 months (IQR: 20.0-49.0 months), 35 patients (4\%) required re-intervention for LUTS relapse in our database. All preoperative data are reported in Table 1 . The median prostate volume of the study population was $60.0 \mathrm{~mL}$ (IQR: $45.0-75.5 \mathrm{~mL}$ ), including 102 patients $(11.8 \%)$ with a prostate volume $\geq 100 \mathrm{~mL}$. No statistical differences were found between the two groups in terms of age, use of antiplatelet and anticoagulant medications, LUTS therapy, and history of catheterization or retention [Table 1]. Patients requiring reintervention had a prostate volume $\geq 100 \mathrm{~mL}$ in $28.6 \%$ of cases $v s .11 .1 \%$ in the no re-treatment group $(P=$ 0.002). Interestingly, preoperative urethral stricture was more frequent in patients undergoing reintervention $(17.1 \%$ vs. $6 \%, P=0.027)$. Intra- and peri-operative data were similar; however, patients requiring reoperation had a higher incidence of early complications [Table 1]. Despite the higher incidence of early complications in the re-treatment group, the type of complications was similar between the two groups [Table 2]. The three most frequent early complications in the treatment failure group and the no retreatment group were burning urination $(25.7 \%$ and $15.3 \%)$, urgency $(17.1 \%$ and $11.5 \%)$, and postoperative urinary retention $(14.3 \%$ and $8.5 \%)$. In addition, the incidence of late complications was higher in the reintervention group, as reported in Table 2. In the re-intervention group, 22 out of 35 patients (62.8\%) required a surgical endoscopic intervention for de novo lower urinary tract symptoms linked to bladder neck or prostatic fossa contracture. In particular, bladder neck and prostatic fossa contracture were more frequent in the patient group undergoing re-intervention $(37.1 \% v$ s. $0.7 \%$ and $25.7 \% v$ s. $0.6 \%$, respectively, $P$ $<0.001)$. Contrariwise, no patients required surgical intervention for these complications in the control group because these did not affect urodynamic patterns. In fact, the Qmax and the PGI-I were better in patients not requiring re-intervention [Tables 2 and 3]. The remaining 12 patients $(1.4 \%$ of the study population) in the re-treatment group underwent a second PVP or a TURP for LUTS relapse after surgery. 
Table 2. Type of complications

\begin{tabular}{|c|c|c|c|c|c|}
\hline Complications & $\begin{array}{l}\text { Clavien-Dindo } \\
\text { grade }\end{array}$ & $\begin{array}{l}\text { No re-intervention } \\
n=832\end{array}$ & $\begin{array}{l}\text { Re-intervention } \\
n=35\end{array}$ & $\begin{array}{l}\text { Overall } \\
n=867\end{array}$ & $\begin{array}{l}P \\
\text { value }\end{array}$ \\
\hline \multicolumn{6}{|l|}{ Perioperative } \\
\hline Prostatic capsule perforation & IIla & $6(0.7 \%)$ & $0(0.0 \%)$ & $6(0.7 \%)$ & 0.614 \\
\hline \multicolumn{6}{|l|}{ Early (< 30 days) } \\
\hline Fever $<38^{\circ} \mathrm{C}$ & I & $15(1.8 \%)$ & $1(2.9 \%)$ & $16(1.8 \%)$ & 0.650 \\
\hline Fever $>38^{\circ} \mathrm{C}$ & । & $23(2.8 \%)$ & $1(2.9 \%)$ & $24(2.8 \%)$ & 0.974 \\
\hline Burning urination & I & $127(15.3 \%)$ & $9(25.7 \%)$ & $136(15.7 \%)$ & 0.096 \\
\hline Frequency & । & $66(7.9 \%)$ & $2(5.7 \%)$ & $68(7.8 \%)$ & 0.633 \\
\hline De novo urge & I & $96(11.5 \%)$ & $6(17.1 \%)$ & $102(11.8 \%)$ & 0.313 \\
\hline Urge incontinence & I & $54(6.5 \%)$ & $4(11.4 \%)$ & $58(6.7 \%)$ & 0.252 \\
\hline Stress incontinence & 1 & $38(4.6 \%)$ & $3(8.6 \%)$ & $41(4.7 \%)$ & 0.274 \\
\hline Hematuria & I & $24(2.9 \%)$ & $1(2.9 \%)$ & $25(2.9 \%)$ & 0.992 \\
\hline Retention & I & $71(8.5 \%)$ & $5(14.3 \%)$ & $76(8.8 \%)$ & 0.238 \\
\hline UTI & $\|$ & $10(1.2 \%)$ & $1(2.9 \%)$ & $11(1.3 \%)$ & 0.391 \\
\hline Blood transfusion & $\|$ & $4(0.5 \%)$ & $0(0.0 \%)$ & $4(0.5 \%)$ & 0.681 \\
\hline MACE & $\mathrm{IVb}$ & $6(0.7 \%)$ & $1(2.9 \%)$ & $7(0.8 \%)$ & 0.167 \\
\hline \multicolumn{6}{|l|}{ Late complication } \\
\hline Stress incontinence & 1 & $26(3.1 \%)$ & $1(2.9 \%)$ & $27(3.1 \%)$ & 0.929 \\
\hline $\begin{array}{l}\text { Bladder neck/prostatic fossa contracture } \\
\text { requiring reintervention }\end{array}$ & IIlb & $0(0 \%)$ & $22(62.8 \%)$ & $22(2.6 \%)$ & $<0.001$ \\
\hline $\mathrm{BPH}$ recurrence requiring surgical reintervention & IIIb & $0(0 \%)$ & $13(37.2 \%)$ & $13(1.4 \%)$ & $<0.001$ \\
\hline Patient global impression of improvement & & & & & 0.003 \\
\hline । & & $401(51.5 \%)$ & $11(34.4 \%)$ & $412(50.9 \%)$ & \\
\hline ॥ & & $291(37.4 \%)$ & $11(34.4 \%)$ & $302(37.3 \%)$ & \\
\hline III & & $62(8.0 \%)$ & $6(18.8 \%)$ & $68(8.4 \%)$ & \\
\hline IV & & $16(2.1 \%)$ & $3(9.4 \%)$ & $19(2.3 \%)$ & \\
\hline V & & $5(0.6 \%)$ & $0(0.0 \%)$ & $5(0.6 \%)$ & \\
\hline VI & & $3(0.4 \%)$ & $1(3.1 \%)$ & $4(0.5 \%)$ & \\
\hline
\end{tabular}

Interestingly, there were no differences in PSA changing and IPSS between the two groups at the follow-up visit [Table 3]. At the univariate and multivariate logistic regression models only prostate volume $\geq 100 \mathrm{~mL}$ $(P=0.003$ and $P=0.010)$, preoperative urethral stricture $(P=0.013$ and $P=0.036)$, and occurrence of early complications $(P=0.008$ and $P=0.024)$ were associated with re-intervention [Table 4].

\section{DISCUSSION}

Despite the great interest in greenlight treatment for BPO, few data are available on long-term follow up and even fewer on failure predictors. These aspects depend on the novelty of this technology. The last development of greenlight was the 180-W XPS launched in 2010. The Goliath Trial, designed at the beginning of the greenlight 180-W XPS experience in 2011, with 128 patients and 2 years of follow-up, described non-inferiority compared to TURP, with $9 \%$ re-treatment rate $v s .7 .6 \%$ in the TURP group ${ }^{[15]}$. In this study, the mean prostate volume was $48.6 \pm 19.2 \mathrm{~mL}$. However, these data have been overcome by some retrospective papers. Ajib et al ${ }^{[16]}$ described a re-intervention rate of $2.6 \%$ at 12 months for bladder neck contracture and a re-intervention for LUTS relapse of $0.5 \%, 0.7 \%$, and $4.8 \%$ at 12,24 , and 48 months, respectively. In a previous paper from our database, we reported 24 patients out of 813 (3.1\%) requiring reintervention with a median follow-up period of 17.7 months (IQR: 12-25.8 months) ${ }^{[17]}$. 
Table 3. Main outcomes after photoselective vaporization of the prostate

\begin{tabular}{|c|c|c|c|}
\hline Outcome & Baseline & 6 months & 12 months \\
\hline \multicolumn{4}{|c|}{ PSA ng/mL, median (IQR) } \\
\hline No re-intervention & $2.7(1.6-3.9)$ & $1.3(0.7-2.1)$ & $1.2(0.7-2.0)$ \\
\hline$(n=832)$ & & $(n=439)$ & $(n=501)$ \\
\hline Re-intervention & $2.4(1.3-4.3)$ & $2.0(0.7-3.7)$ & $1.3(0.6-3.6)$ \\
\hline$(n=35)$ & & $(n=10)$ & $(n=17)$ \\
\hline Overall & $2.6(1.6-3.9)$ & $1.3(0.7-2.1)$ & $1.2(0.7-2.0)$ \\
\hline$(n=867)$ & & $(n=449)$ & $(n=518)$ \\
\hline$P$ value & 0.767 & 0.346 & 0.647 \\
\hline \multicolumn{4}{|c|}{ Qmax mL/s, median (IQR) } \\
\hline No re-intervention & $8.7(7.0-10.9)$ & $19.4(16.6-24.0)$ & $19.8(16.9-24.0)$ \\
\hline$(n=832)$ & & $(n=650)$ & $(n=533)$ \\
\hline Re-intervention & $7.0(5.0-9.8)$ & $18.0(16.0-20.9)$ & $18.0(14.4-19.5)$ \\
\hline$(n=35)$ & & $(n=21)$ & $(n=19)$ \\
\hline Overall & $8.7(7.0-10.6)$ & $19.4(16.0-23.5)$ & $19.6(16.5-23.8)$ \\
\hline$(n=867)$ & & $(n=671)$ & $(n=552)$ \\
\hline$P$ value & 0.012 & 0.048 & 0.004 \\
\hline \multicolumn{4}{|l|}{ IPSS, median (IQR) } \\
\hline No re-intervention & $23.0(19.0-27.0)$ & $7.0(5.0-10.0)$ & $5.0(3.0-8.0)$ \\
\hline$(n=832)$ & & $(n=624)$ & $(n=539)$ \\
\hline Re-intervention & $23.5(20.0-27.8)$ & $8.0(6.2-10.0)$ & $5.0(4.0-8.0)$ \\
\hline$(n=35)$ & & $(n=26)$ & $(n=23)$ \\
\hline Overall & $23.0(19.0-27.0)$ & $7.0(5.0-10.0)$ & $5.0(3.0-8.0)$ \\
\hline$(n=867)$ & & $(n=650)$ & $(n=562)$ \\
\hline$P$ value & 0.457 & 0.129 & 0.603 \\
\hline
\end{tabular}

IQR: Interquartile range; Qmax: maximum urinary flow.

Table 4. Univariate and multivariate logistic regression

\begin{tabular}{lllll}
\hline & \multicolumn{2}{c}{ Univariable } & \multicolumn{2}{c}{ Multivariable } \\
\cline { 2 - 5 } & Odds ratio (95\% Cl) & P value & Odds ratio (95\%Cl) & P value \\
\hline Age & $1.00(0.96-1.05)$ & $P=0.843$ & - & - \\
Prostate volume $\geq 100$ & $3.22(1.43-6.73)$ & $P=0.003$ & $2.77(1.22-5.86)$ & $P=0.010$ \\
Antiplatelet/anticoagulant therapy & $0.90(0.44-1.79)$ & $P=0.765$ & - & - \\
BPH/LUTS therapy & & & - & - \\
$\quad$ None & - & - & - & - \\
$\quad$ Alpha-blockers & $1.03(0.42-2.87)$ & $P=0.956$ & - & - \\
$\quad$ 5-ARI & $0.45(0.02-2.76)$ & $P=0.471$ & - & - \\
$\quad$ Combination & $0.79(0.28-2.40)$ & $P=0.660$ & - & $P=0.036$ \\
Indwelling catheter history & $2.09(0.91-4.42)$ & $P=0.064$ & - & - \\
Preoperative urethral stricture & $3.24(1.17-7.67)$ & $P=0.013$ & $2.74(0.97-6.63)$ & \\
Early complications & $2.61(1.31-5.50)$ & $P=0.008$ & - & \\
\hline
\end{tabular}

LUTS: Lower urinary tract symptoms; 5-ARI: 5 alpha-reductase inhibitors.

In this further analysis of our updated, multicenter experience, the rate of re-intervention for bladder neck contracture or LUTS relapse is $4 \%$ (35 out of 867 patients) with longer follow-up (median, 32.5 months, IQR: 20.0-49.0 months; minimum, 12 months). In detail, only 1.4\% (12 patients) underwent a second PVP or a TURP for LUTS relapse. Recently, the Global Greenlight Group published data from 3627 patients who 
underwent greenlight PVP with a median follow-up of 6 months, and the authors reported a re-treatment rate of $1.5 \%$ and an incidence of bladder neck contracture of $1.93 \%$ in 569 patients at 5 -year follow-up ${ }^{[8]}$, in line with our results. Unfortunately, in all cited articles, the authors performed only a descriptive analysis, without analyzing risk factors for treatment failure. In our database analysis, apart from a descriptive analysis of results, we analyzed the possible risk factors of treatment failure after greenlight PVP. In the univariate and multivariate logistic regression models, three factors correlated with re-intervention: preoperative urethral stricture $(P=0.013$ and $P=0.036)$, incidence of early complications $(P=0.008$ and $P=$ $0.024)$, and prostate volume $\geq 100 \mathrm{~mL}(P=0.003$ and $P=0.010)$ [Table 4]. The correlation between the incidence of early complications (burning urination, urgency, and urinary retention) and the risk of retreatment due to LUTS relapse may correlate with inefficacious vaporization due to inadequate adenoma removal with excess energy absorption by the prostatic tissue, a factor which might have an inflammatory and irritating effect. Obviously, this is a hypothesis not confirmed by our data in this analysis. In fact, operative and lasing time as well as PSA changing at 12 months are similar in the two groups $(P=0.778, P=$ 0.978 , and $P=0.674$, respectively). However, in a recent paper of our group, where we analyzed risk factors of postoperative acute urinary retention after greenlight laser procedures, lower lasing time, adenoma volume $<40 \mathrm{~mL}$, IPSS $\geq 19$, and 5 alpha-reductase inhibitors (5-ARI) assumption were associated with a higher risk of postoperative acute urinary retention, implying that an inefficacious vaporization and an inflammatory component may play a role ${ }^{[18]}$.

A further evaluation is necessary for patients with prostate volume $\geq 100 \mathrm{~mL}$. In a recent analysis of ours regarding functional results in patients with large prostate volume, the re-intervention rate in the $\geq 100 \mathrm{~mL}$ group was $3.5 \%$ vs. $2.3 \%$ in the group with prostate volume $<100 \mathrm{~mL}$ with a mean follow-up of 25.0 months (IQR: 16.5-35.0 months) ${ }^{[10]}$. In the literature, the re-intervention rate of patients undergoing greenlight PVP for large prostate volume is reported as $15.2 \%$ by Laine-Caroff (with a median follow-up of 54 months) ${ }^{[19]}$, $13.2 \%$ by Meskawi et al. ${ }^{[20]}, 6 \%$ for $200 \mathrm{~mL}$ prostate and $9 \%$ for $100-200 \mathrm{~mL}$ in a multi-institutional series ${ }^{[21]}$, $2.9 \%{ }^{[22]}, 1.2 \%^{[23]}$, and no re-treatment at 12 months reported by Altay et al. ${ }^{[24]}$. In these papers, larger prostate volume, low energy density, and a lower PSA reduction at 6 months after surgery ${ }^{[20]}$ or low energy density ${ }^{[23]}$ are reported as risk factors for treatment failure.

Despite the good functional results associated with low morbidity, in these vaporization series, a large prostate is a consideration which should be made concerning the enucleation technique. In a recent nationwide database, including 58,346 patients (38,308 TURP and 20,038 HoLEP), the authors reported a higher reoperation rate in the TURP group (4.50\%) than in the HoLEP group $(1.27 \%)(P<0.01)$ with mean follow-up durations of 51.6 and 47.6 months, respectively ${ }^{[25]}$.

These data are in line with a randomized trial comparing greenlight PVP vs. B-TURP vs. HoLEP in large prostate (80-150 mL), with 3 years of follow-up and a re-treatment rate of $6.7 \%, 9.7 \%$, and $0 \%$, respectively ${ }^{[26]}$. The authors postulated that pure enucleation may guarantee longer functional results than vaporization or resection techniques. The experience in GreenLEP reported by Ferrari et al. ${ }^{[27]}$ with a study population of 120 patients, a median prostate volume of $98.5 \mathrm{~mL}$ (IQR: 83.0-130.0 mL), and a median follow-up of 18 months seems to go in this direction, with no reoperation. Obviously, more studies are needed to confirm this finding.

Some limitations are present in our study, the first being the retrospective nature and the participation of 20 centers. An additional issue to be taken into consideration is the absence of enucleation procedures. Nevertheless, the follow-up period is one of the longest in the literature. In our experience, the re-treatment rate of $1.4 \%$ and the $2.6 \%$ rate of bladder neck contracture requiring endoscopic revision after a median of 
23 months postoperatively are in line with results from other greenlight and TURP series. Prostate volume $\geq$ $100 \mathrm{~mL}$, preoperative urethral stricture, and the early-onset complications correlate with the re-treatment risk. Greenlight PVP has good functional long/mid-term results. The presence of preoperative urethral stricture and the occurrence of early complications correlate with the risk of late re-treatment. In patients with prostate $\geq 100 \mathrm{~mL}$, the enucleation technique may be superior to vaporization in terms of lower longterm risk of re-intervention for a LUTS relapse.

\section{DECLARATIONS}

\section{Authors' contributions}

Conception and design: Campobasso D, Cindolo L

Data acquisition: Greco F, De Nunzio C, Destefanis P, Varvello F, Reale G, Cai T, Malossini G, Oriti R, Tuccio A, Ruggera L, Laganà A, Dadone C, De Rienzo G, Pucci L, Montefiore F, Rabito S, Germani S

Data analysis and interpretation: Campobasso D, Marchioni M, Cindolo L

Drafting the manuscript: Campobasso D, Cindolo L

Critical revision of the manuscript for scientific and factual content: Greco F, De Nunzio C, Ferrari G

Statistical analysis: Marchioni M

Supervision: Destefanis P, Fasolis G, Voce S, Cai T, Ruggera L, Tubaro A, Dadone C, Gontero P, Carrino M, Miano R, Schips L, Frattini A

\section{Availability of data and materials}

Not applicable.

\section{Financial support and sponsorship}

None.

\section{Conflict of interest}

Destefanis P, Ruggera L, Dadone C, Ferrari G and Cindolo L do surgical tutorship for American Medical System and received honoraria for their tutorship.

\section{Ethical approval and consent to participate}

Written informed consent was obtained from all patients.

\section{Consent for publication}

Not applicable.

\section{Copyright}

(c) The Author(s) 2021.

\section{REFERENCES}

1. Lieber MM, Rhodes T, Jacobson DJ, et al. Natural history of benign prostatic enlargement: long-term longitudinal population-based study of prostate volume doubling times. BJU Int 2010;105:214-9. DOI PubMed PMC

2. Gravas S, Cornu JN, Gacci M, et al. EAU guidelines on management of non-neurogenic male lower urinary tract symptoms (LUTS), incl. Benign prostatic obstruction (BPO). Netherlands: European Association of Urology; 2015. DOI

3. Cindolo L, Pirozzi L, Fanizza C, et al. Drug adherence and clinical outcomes for patients under pharmacological therapy for lower urinary tract symptoms related to benign prostatic hyperplasia: population-based cohort study. Eur Urol 2015;68:418-25. DOI PubMed

4. Falavolti C, Petitti T, Buscarini M. Robot-assisted simple prostatectomy with temporary internal iliac arteries clamping: our preliminary results. Mini-invasive Surg 2017;1:35-40. DOI

5. Gu C, Zhou N, Gurung P, et al. Lasers versus bipolar technology in the transurethral treatment of benign prostatic enlargement: a systematic review and meta-analysis of comparative studies. World J Urol 2020;38:907-18. DOI PubMed

6. Campobasso D, Ferrari G, Frattini A. Greenlight laser: a laser for every prostate and every urologist. World J Urol 2020. DOI PubMed 
7. Cindolo L, Ruggera L, Destefanis P, Dadone C, Ferrari G. Vaporize, anatomically vaporize or enucleate the prostate? Int Urol Nephrol 2017;49:405-11. DOI PubMed

8. Law KW, Tholomier C, Nguyen DD, et al. Global Greenlight Group: largest international Greenlight experience for benign prostatic hyperplasia to assess efficacy and safety. World J Urol 2021. DOI PubMed

9. Meskawi M, Hueber PA, Valdivieso R, et al. Complications and functional outcomes of high-risk patient with cardiovascular disease on antithrombotic medication treated with the 532-nm-laser photo-vaporization Greenlight XPS-180 W for benign prostate hyperplasia. World J Urol 2019;37:1671-8. DOI PubMed

10. Campobasso D, Marchioni M, Altieri V, et al. GreenLight photoselective vaporization of the prostate: one laser for different prostate sizes. J Endourol 2020;34:54-62. DOI PubMed

11. Leonardo C, Lombardo R, Cindolo L, et al; AGILE Group. What is the standard surgical approach to large volume BPE? Minerva Urol Nefrol 2020;72:22-9. DOI PubMed

12. De Nunzio C, Lombardo R, Autorino R, et al. Contemporary monopolar and bipolar transurethral resection of the prostate: prospective assessment of complications using the Clavien system. Int Urol Nephrol 2013;45:951-9. DOI PubMed

13. Mamoulakis C, Efthimiou I, Kazoulis S, Christoulakis I, Sofras F. The modified Clavien classification system: a standardized platform for reporting complications in transurethral resection of the prostate. World J Urol 2011;29:205-10. DOI PubMed PMC

14. Hossack T, Woo H. Validation of a patient reported outcome questionnaire for assessing success of endoscopic prostatectomy. Prostate Int 2014;2:182-7. DOI PubMed PMC

15. Thomas JA, Tubaro A, Barber N, et al. A multicenter randomized noninferiority trial comparing greenlight-XPS laser vaporization of the prostate and transurethral resection of the prostate for the treatment of benign prostatic obstruction: two-yr outcomes of the GOLIATH study. Eur Urol 2016;69:94-102. DOI PubMed

16. Ajib K, Mansour M, Zanaty M, et al. Photoselective vaporization of the prostate with the 180-W XPS-Greenlight laser: five-year experience of safety, efficiency, and functional outcomes. Can Urol Assoc J 2018;12:E318-24. DOI PubMed PMC

17. Cindolo L, De Nunzio C, Greco F, et al; Members of Green Laser Italian Group. Standard vs. anatomical 180-W GreenLight laser photoselective vaporization of the prostate: a propensity score analysis. World J Urol 2018;36:91-7. DOI PubMed

18. Campobasso D, Acampora A, De Nunzio C, et al. Post-operative acute urinary retention after greenlight laser. Analysis of risk factors from a multicentric database. Urol J 2021. DOI PubMed

19. Laine-Caroff P, Pradere B, Ruffion A, Bruyere F. Greenlight laser photoselective vaporization vs open simple prostatectomy: longterm functional outcomes after treatment of large volume prostates (> 80 cc). Int Urol Nephrol 2021;53:1289-95. DOI PubMed

20. Meskawi M, Hueber PA, Valdivieso R, et al. Multicenter international experience of $532 \mathrm{~nm}$-laser photo-vaporization with Greenlight XPS in men with large prostates (prostate volume > $100 \mathrm{cc}$ ). World J Urol 2017;35:1603-9. DOI PubMed

21. Valdivieso R, Hueber PA, Meskawi M, et al. Multicentre international experience of 532-nm laser photoselective vaporization with GreenLight XPS in men with very large prostates. BJU Int 2018;122:873-8. DOI PubMed

22. Stone BV, Chughtai B, Forde JC, Tam AW, Lewicki P, Te AE. Safety and efficacy of GreenLight XPS laser vapoenucleation in prostates measuring over $150 \mathrm{~mL}$. J Endourol 2016;30:906-12. DOI PubMed

23. Hueber PA, Bienz MN, Valdivieso R, et al. Photoselective vaporization of the prostate for benign prostatic hyperplasia using the 180 Watt system: multicenter study of the impact of prostate size on safety and outcomes. J Urol 2015;194:462-9. DOI PubMed

24. Altay B, Erkurt B, Kiremit MC, Guzelburc V, Boz MY, Albayrak S. 180-W XPS GreenLight laser vaporization for benign prostate hyperplasia: 12-month safety and efficacy results for glands larger than $80 \mathrm{~mL}$. Lasers Med Sci 2015;30:317-23. DOI PubMed

25. Kim A, Hak AJ, Choi WS, Paick SH, Kim HG, Park H. Comparison of long-term effect and complications between holmium laser enucleation and transurethral resection of prostate: nations-wide health insurance study. Urology 2021;154:300-7. DOI PubMed

26. Elshal AM, Soltan M, El-Tabey NA, Laymon M, Nabeeh A. Randomised trial of bipolar resection vs holmium laser enucleation vs Greenlight laser vapo-enucleation of the prostate for treatment of large benign prostate obstruction: 3-years outcomes. BJU Int 2020;126:731-8. DOI PubMed

27. Ferrari G, Rabito S, Gatti L, et al. Green Light laser enucleation of the prostate with early apical release is safe and effective: single center experience and revision of the literature. Minerva Urol Nephrol 2021. DOI PubMed 